\title{
Contribution of Alanine-76 and Serine Phosphorylation in $\alpha$-Synuclein Membrane Association and Aggregation in Yeasts
}

\author{
Michael Fiske, Stephanie Valtierra, Keith Solvang, Michael Zorniak, Michael White, \\ Sara Herrera, Alina Konnikova, Rebecca Brezinsky, and Shubhik DebBurman
}

Biology Department, Lake Forest College, Box P7, 555 North Sheridan Road, Lake Forest, IL 60045, USA

Correspondence should be addressed to Shubhik DebBurman, debburman@lfc.edu

Received 14 February 2011; Accepted 1 April 2011

Academic Editor: T. M. Dawson

Copyright (C) 2011 Michael Fiske et al. This is an open access article distributed under the Creative Commons Attribution License, which permits unrestricted use, distribution, and reproduction in any medium, provided the original work is properly cited.

\begin{abstract}
In Parkinson's disease (PD), misfolded and aggregated $\alpha$-synuclein protein accumulates in degenerating midbrain dopaminergic neurons. The amino acid alanine-76 in $\alpha$-synuclein and phosphorylation at serine-87 and serine-129 are thought to regulate its aggregation and toxicity. However, their exact contributions to $\alpha$-synuclein membrane association are less clear. We found that $\alpha$ synuclein is indeed phosphorylated in fission yeast and budding yeast, the two models that we employed for assessing $\alpha$-synuclein aggregation and membrane association properties, respectively. Surprisingly, blocking serine phosphorylation (S87A, S129A, and S87A/S129A) or mimicking it (S87D, S129D) altered $\alpha$-synuclein aggregation in fission yeast. Either blocking or mimicking this phosphorylation increased endomembrane association in fission yeast, but only mimicking it decreased plasma membrane association in budding yeast. Polar substitution mutations of alanine-76 (A76E and A76R) decreased $\alpha$-synuclein membrane association in budding yeast and decreased aggregation in fission yeast. These yeast studies extend our understanding of serine phosphorylation and alanine-76 contributions to $\alpha$-synuclein aggregation and are the first to detail their impact on $\alpha$-synuclein's plasma membrane and endomembrane association.
\end{abstract}

\section{Introduction}

The $\alpha$-synucleinopathies are a group of neurodegenerative diseases that include Parkinson's disease, dementia with Lewy bodies (DLB), multiple system atrophy (MSA), and Lewy body dysphagia [1-4]. Each disease is characterized by neuronal death and accumulation of $\alpha$-synuclein and several other proteins in cytoplasmic inclusions called Lewy bodies [5]. Of these, PD is the most prevalent disorder, afflicting over 4 million people worldwide [6]. While whether the aggregation of $\alpha$-synuclein is neurotoxic or a protective cellular response is still being resolved, $\alpha$-synuclein is intimately linked to pathogenesis as Lewy bodies are found in both sporadic and familial PD, and three point mutations (A53T, $\mathrm{A} 30 \mathrm{P}$, and $\mathrm{E} 46 \mathrm{~K}$ ) within the $\alpha$-synuclein gene itself cause PD [7-9]. Duplication or triplication of the $\alpha$-synuclein locus also results in PD onset, further implicating $\alpha$-synuclein in $\mathrm{PD}$ pathogenesis $[10,11]$. Even sporadic PD is linked to polymorphisms in the $\alpha$-synuclein gene that potentially increase protein production [12].
$\alpha$-Synuclein is a short, highly flexible protein found throughout the brain and localized to presynaptic terminals of dopaminergic neurons [13-15]. Two biochemical properties of $\alpha$-synuclein most clearly linked to PD pathology are intracellular aggregation [16] and membrane association [17], but how each contributes to cellular toxicity is still being sorted. Additionally, several factors are thought to influence both these $\alpha$-synuclein properties, including posttranslational modifications such as ubiquitination [18], glycosylation [18], nitration [18-20], and phosphorylation [21, 22], as well as specific amino acids within the protein's three domains, especially its middle NAC domain [19, 23, 24]. This study specifically focused on the amino acid alanine-76 within the NAC domain and on serine phosphorylation.

Within Lewy bodies, $\alpha$-synuclein is heavily phosphorylated at serine-129 and serine-87 [21, 22, 25]. The role of phosphorylation has been studied in several model systems with conflicting findings [22, 26-30]. A study in flies found that phosphorylation enhanced $\alpha$-synuclein toxicity [27], 
while other research in mice and rats concluded that phosphorylation was neuroprotective $[28,29]$. Still another study in rats saw no change in toxicity due to phosphorylation [30]. Additionally, some work suggests that phosphorylation enhances aggregation $[22,26,28]$, while others suggest that aggregation decreases when $\alpha$-synuclein is phosphorylated $[25,27,30]$. The link between membrane association and phosphorylation is considerably less well studied, with only a single in vitro study suggesting that serine- 87 phosphorylation inhibits membrane association [25]. More research is needed to clarify the role of serine phosphorylation in $\alpha$ synuclein toxicity, aggregation, and membrane association.

$\alpha$-Synuclein is comprised of three domains that contribute differentially to the protein's properties. The amino domain (1-60) forms an amphipathic $\alpha$-helix upon binding to lipids [31]. The NAC domain (61-95) is highly amyloidogenic and mostly closely linked to aggregation and fibril formation [32]. The carboxyl domain (96-140) opposes aggregation and is typically truncated in Lewy bodies [33]. $\alpha$-Synuclein has a natural tendency to aggregate due to its flexible structure [34], and the NAC domain of $\alpha$-synuclein is needed for this aggregation $[13,32,35,36]$. Deletion of amino acids $71-82$ within the NAC domain significantly decreases $\alpha$-synuclein aggregation in vitro $[19,37]$ and in cell culture [38]. Within this domain, alanine-76 has been mathematically predicted to contribute to aggregation of the protein [23], and the combined deletion of alanine-76 and valine-77 reduces the formation of aggregates in vitro [37]. However, the contributions of alanine-76 to aggregation have not been assessed in other organismal models, especially yeast, where contributions to membrane association can additionally be evaluated.

A number of successful budding yeast (Saccharomyces cerevisiae) model systems for $\alpha$-synuclein aggregation, membrane association, and toxicity have been established since 2003 [38-44]. Additionally, our lab pioneered a fission yeast $\alpha$-synuclein model in 2006, marking the first time Schizosaccharomyces pombe had been used to model PDassociated $\alpha$-synuclein properties [45]. These two yeast systems provide a unique research opportunity to comparatively study how $\alpha$-synuclein exhibits aggregation and membrane association properties in each organism. In budding yeast, we and others find that $\alpha$-synuclein associates with the plasma membrane when expressed at moderate levels [38, 40-42]. In fission yeast, we reported that $\alpha$-synuclein forms aggregatelike inclusions within the yeast cell in a concentrationdependent manner, but it rarely associates with the plasma membrane [45]. Thus, each yeast model recapitulates an important PD-related property of $\alpha$-synuclein (aggregation or membrane association), allowing us to determine how serine phosphorylation and alanine-76 impact these two pathologically linked properties of $\alpha$-synuclein.

In this study, we hypothesized that phosphorylation contributes to membrane association of $\alpha$-synuclein, which we tested by generating phosphorylation-deficient (S87A, S129A, and S87A/S129A) and phosphorylationmimic (S87D and S129D) $\alpha$-synuclein mutants. We also created nonpolar to polar (A76E and A76R) $\alpha$-synuclein

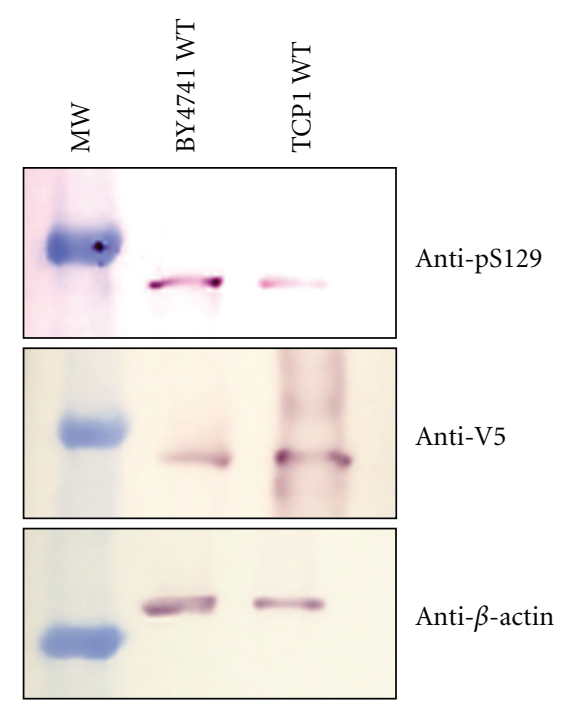

FIgURE 1: WT $\alpha$-synuclein is phosphorylated at serine-129 in both yeasts. Western blot of BY4741 WT and TCP1WT lysates probed with anti-pS129 (top), anti-V5 ( $\alpha$-synuclein; middle), and protein loading control anti- $\beta$-actin (bottom). WT $\alpha$-synuclein is phosphorylated at serine-129 in both yeasts.

mutants to evaluate alanine-76's contributions to membrane association. We report that serine phosphorylation altered $\alpha$-synuclein's interaction with membrane systems: endomembrane structures of fission yeast and the plasma membrane in budding yeast. We also found that alanine-76 contributed significantly to $\alpha$-synuclein membrane association in budding yeast and regulated $\alpha$-synuclein aggregation in fission yeast. Neither serine phosphorylation nor alanine76 significantly affected toxicity in either yeast model.

\section{Results}

2.1. Wild-Type $\alpha$-Synuclein Is Phosphorylated in Both Yeast Models. To date, only one study has reported that wildtype (WT) $\alpha$-synuclein is phosphorylated in a budding yeast model for studying PD-related properties [46], but none have been reported for fission yeast. An antibody is readily available for serine- 129 phosphorylated $\alpha$-synuclein (ab59264; Abcam), but not for phosphorylation at serine87 , so we probed lysates from BY4741 budding yeast and TCP1 fission yeast cells expressing WT $\alpha$-synuclein with this anti-pS129 antibody. The Western blot showed that WT $\alpha$ synuclein is phosphorylated at serine-129 in each of our yeast models (Figure 1).

\subsection{Phosphorylation Mutants Alter $\alpha$-Synuclein Localization} in Fission Yeast in Complex Ways. We first assessed our phosphorylation mutants in fission yeasts, which best recapitulates $\alpha$-synuclein aggregation [45]. We referred to the $\alpha$ synuclein localization pattern in fission yeasts as "aggregates" in our initial study [45] and do so again here, as they are distinct intracellular accumulations that are different from the plasma membrane or the vesicular membrane localization of $\alpha$-synuclein-GFP in budding yeast. We acknowledge 
that for these puncta to be defined as true aggregates electron microscopy is required and that is an experiment that we have yet to perform. Using the anti-pS129 antibody, we determined that WT and S87A $\alpha$-synuclein were phosphorylated at serine-129 while S129A was not (Figure 2(a)). S87D was also phosphorylated at S129, but S129D was not, indicating that the antibody recognizes the phosphate group added to serine-129 rather than the overall shape of phosphorylated $\alpha$-synuclein (Figure 2(a)). As expected, the antibody did not recognize the double mutant S87A/S129A (Figure 2(a)). An antibody for V5 shows that mutants and WT $\alpha$-synuclein were all expressed (Figure 2(a)).

We then assessed if our phosphorylation mutants altered $\alpha$-synuclein aggregation, the phenotype we previously reported in fission yeast [45]. The phosphorylationdeficient mutants decreased $\alpha$-synuclein aggregation at both 24 and 48 hours of expression (Figure 2(b), top). Instead, the phosphorylation-deficient mutants enhanced association with intracellular membranous, especially perinuclear, compartments, with over $90 \%$ of fluorescing cells exhibiting this phenotype (Figure 2(b)-bottom). The phosphorylationmimic mutants also altered $\alpha$-synuclein localization: S87D $\alpha$-synuclein increased localized to the cytoplasm (15\%) compared to WT $(0 \%)$ in fission yeast at 24 hours (Figure 2(b)bottom), while S129D $\alpha$-synuclein demonstrated a pattern surprisingly similar to phosphorylation-deficient mutants at 24 hours but became aggregated similar to WT $\alpha$-synuclein levels by 48 hours (Figure 2(b)-bottom).

Lastly, given the significant impact on $\alpha$-synuclein aggregation, we examined whether the phosphorylation mutants modified $\alpha$-synuclein toxicity in fission yeast where WT $\alpha$-synuclein is itself moderately toxic (Fiske et al., 2011, in press ISRN Neurology). We assessed fivefold serial dilution spotting and found that surprisingly neither the phosphorylation-mimic nor phosphorylation-deficient mutants altered the level of toxicity already exhibited by WT $\alpha$-synuclein (Figure 2(c)).

2.3. Phosphorylation Mutants Slightly Alter $\alpha$-Synuclein Membrane Binding in Budding Yeast. Whether serine phosphorylation regulates $\alpha$-synuclein membrane association has not previously been reported. Therefore, we next assessed phosphorylation mutants in our budding yeast model, where WT $\alpha$-synuclein associates with the plasma membrane when expressed at moderate levels [41]. We first examined phosphorylation status and expression with the anti-pS129 antibody. WT and S87A $\alpha$-synuclein were phosphorylated at serine-129 while the S129A mutant was not (Figure 3(a)), just as seen in fission yeast. S87D $\alpha$-synuclein was also phosphorylated at serine-129, but the S129D phosphorylationmimic mutant was not (Figure 3(a)). V5 immunoblotting shows that phosphorylation mutants and WT $\alpha$-synuclein were expressed in all cells (Figure 3(a)).

Next, we evaluated where the phosphorylation mutants localized relative to WT $\alpha$-synuclein in budding yeast. All phosphorylation-deficient $\alpha$-synuclein mutants localized primarily to the plasma membrane of cells at 24 and 48 hours ( $85 \%$ of cells), as indicated by live-cell GFP microscopy and quantification (Figure $3(\mathrm{~b})$ ). In contrast, more than half the cells expressing phosphorylation-mimic mutants localized $\alpha$-synuclein to the cytoplasm at 24 hours $(66 \%$ for S87D $\alpha$-synuclein and 57\% for S129D $\alpha$-synuclein). By 48 hours, however, S87D and S129D $\alpha$-synuclein localized to the plasma membrane (70\%), almost to WT $\alpha$ synuclein and the phosphorylation-deficient mutants levels (Figure 3(b)). Therefore, the cytoplasmic localization of the phosphorylation-mimic mutants was temporary.

Lastly, given this moderate impact of phosphorylation on membrane association, we assessed whether it was enough to regulate cellular toxicity. Previously, we reported that WT $\alpha$-synuclein was not toxic to budding yeast ([41]; and Fiske et al. in press ISRN Neurology). Serial dilution spotting on solid plate media revealed no change in growth of budding yeast cells expressing any of the $\alpha$-synuclein phosphorylation mutants in comparison to cells expressing the empty vector, GFP, or WT $\alpha$-synuclein (Figure 3(c)).

\subsection{A76E and A76R Mutants Differentially Alter $\alpha$-Synuclein} Localization in Fission Yeast. We next sought to characterize alanine-76 in our yeast models by examining the A76E and A76R mutants in fission yeast. Both mutants altered $\alpha$-synuclein aggregation patterns. Compared to WT $\alpha$ synuclein, A76E $\alpha$-synuclein strongly localized throughout the cytoplasm of the fission yeast cells (78\%) with only minor intracellular puncta forming by 24 hours of expression (Figure 4(a)-right). It remained in the cytoplasm after 48 hours $(71 \%)$, although more prominent aggregates formed by this time. A76R $\alpha$-synuclein also localized to the cytoplasm by 24 hours (68\%), but some cells began to exhibit endomembrane localization (Figure 4(a)). By 48 hours, this A76R endomembrane localization pattern became even more prominent, and different from the kind of aggregates seen with WT and A76E $\alpha$-synuclein. Unexpectedly, some $\alpha$ synuclein plasma membrane association was also apparent at 24 and 48 hours with A76R $\alpha$-synuclein (Figure 4(a)-left), suggesting that this mutant might actually confer affinity for plasma membranes.

Next, we determined whether the A76E and A76R mutants altered WT $\alpha$-synuclein level of toxicity in fission yeast. Fivefold serial dilution spotting revealed no change in growth between cells expressing WT $\alpha$-synuclein and the two alanine-76 mutants (Figure 4(b)).

Lastly, we assessed $\alpha$-synuclein expression levels in cells expressing WT, A76E, or A76R $\alpha$-synuclein. No significant difference in expression was observed in cells expressing WT, A76E, or A76R $\alpha$-synuclein at 24 or 48 hours (Figure $4(\mathrm{c})$ ).

\subsection{Alanine-76 Mutants Alter Localization in Budding Yeast} without Inducing Toxicity. Finally, we characterized alanine76 effects on plasma membrane association by studying the A76E and A76R mutants in budding yeast. Indeed, both $\mathrm{A} 76 \mathrm{E}$ and A76R $\alpha$-synuclein increased localization to the cytoplasm of the yeast at 24 hours after induction (60\%), although many cells retained some membrane association as well (Figure 5(a)-right). However, unlike A76E, which remained in the cytoplasm (62\%), the A76R $\alpha$-synuclein 


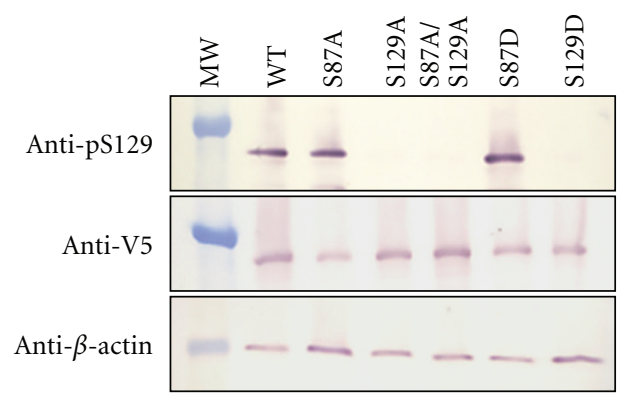

(a) Expression
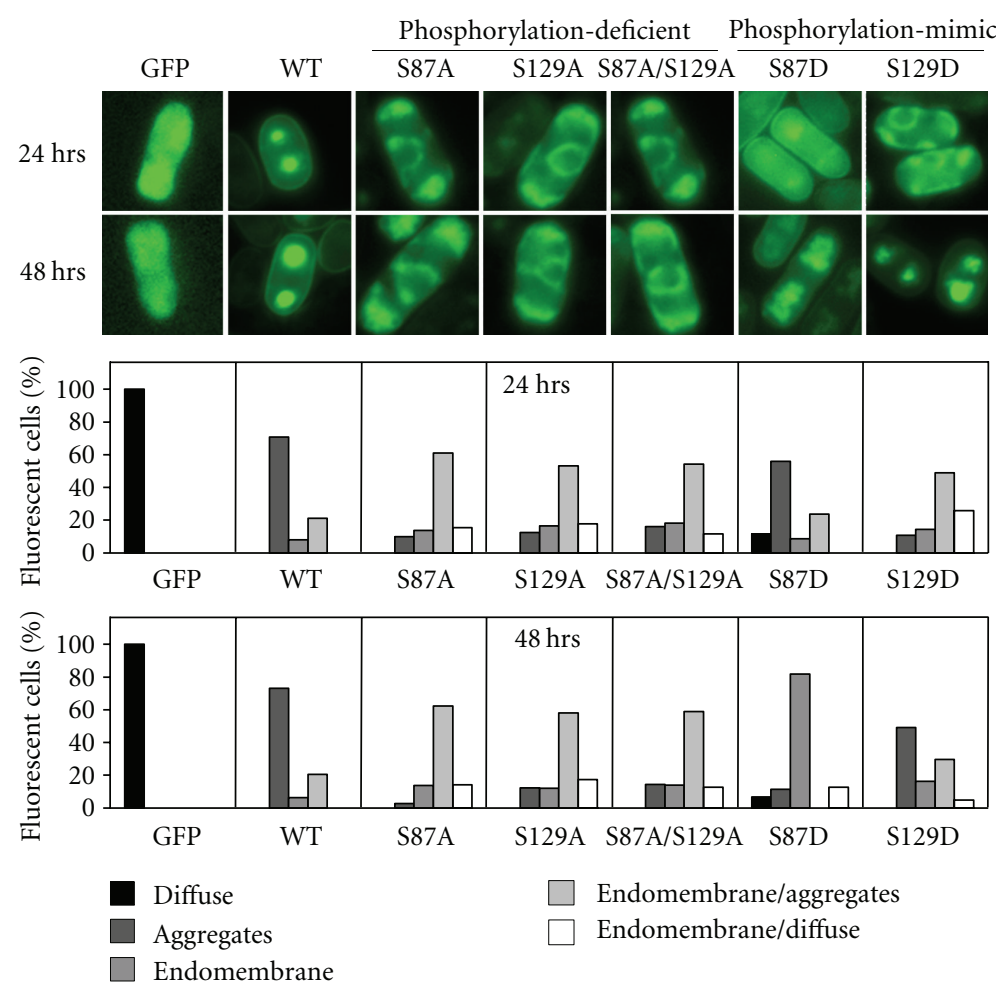

(b) Localization \& Quantification

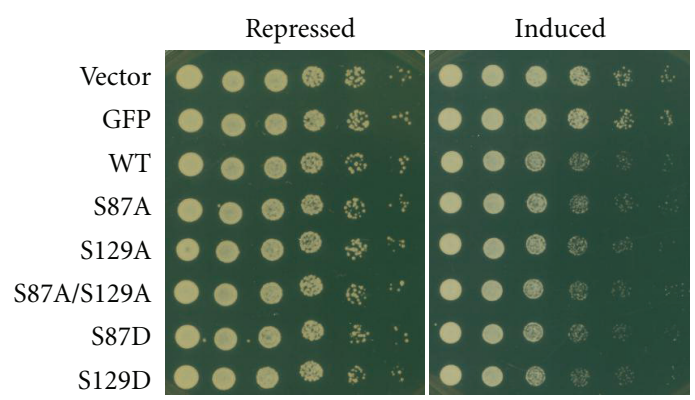

(c) Toxicity

FIGURE 2: Characterization of phosphorylation mutants in TCP1. (a) Western blot of WT, phosphorylation-deficient mutants (S87A, S129A, and S87A/S129A), and phosphorylation-mimic mutants (S87D, S129D). TCP1 lysates were probed with anti-pS129 (top), antiV5 ( $\alpha$-synuclein; middle), and anti- $\beta$-actin (bottom) $(N=3)$. (b) Live-cell GFP microscopy of TCP1 cells expressing GFP, WT, S87A, S129A, S87A/S129A, S87D, or S129D at 24 and 48 hours (top). Quantification: 750 cells of each type were scored for these localization patterns: cytoplasmically diffuse, aggregate, endomembrane, endomembrane/diffuse, and endomembrane/aggregate (bottom). Phenotypes were plotted as a percent of total cells that fluoresced $(N=2)$. (c) Cells expressing WT, S87A, S129A, S87A/S129A, S87D, or S129D were grown in inducing (EMM-T) media for 48 hours. Vector alone and GFP served as controls. Equal number of cells were serially diluted 5 -fold and spotted onto repressing $(\mathrm{EMM}+\mathrm{T})$ or inducing $(\mathrm{EMM}-\mathrm{T})$ plates and grown for two days (bottom). No phosphorylation-specific toxicity was apparent in either assay $(N=3)$. 


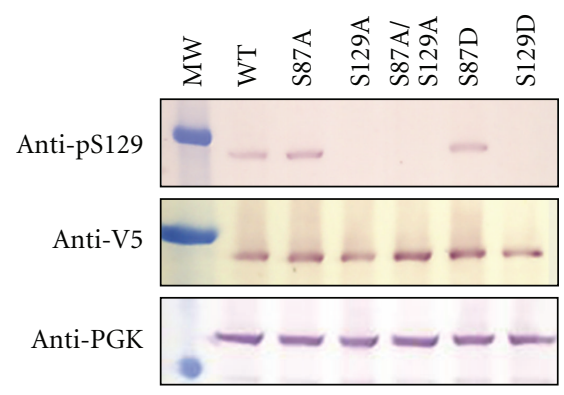

(a) Expression
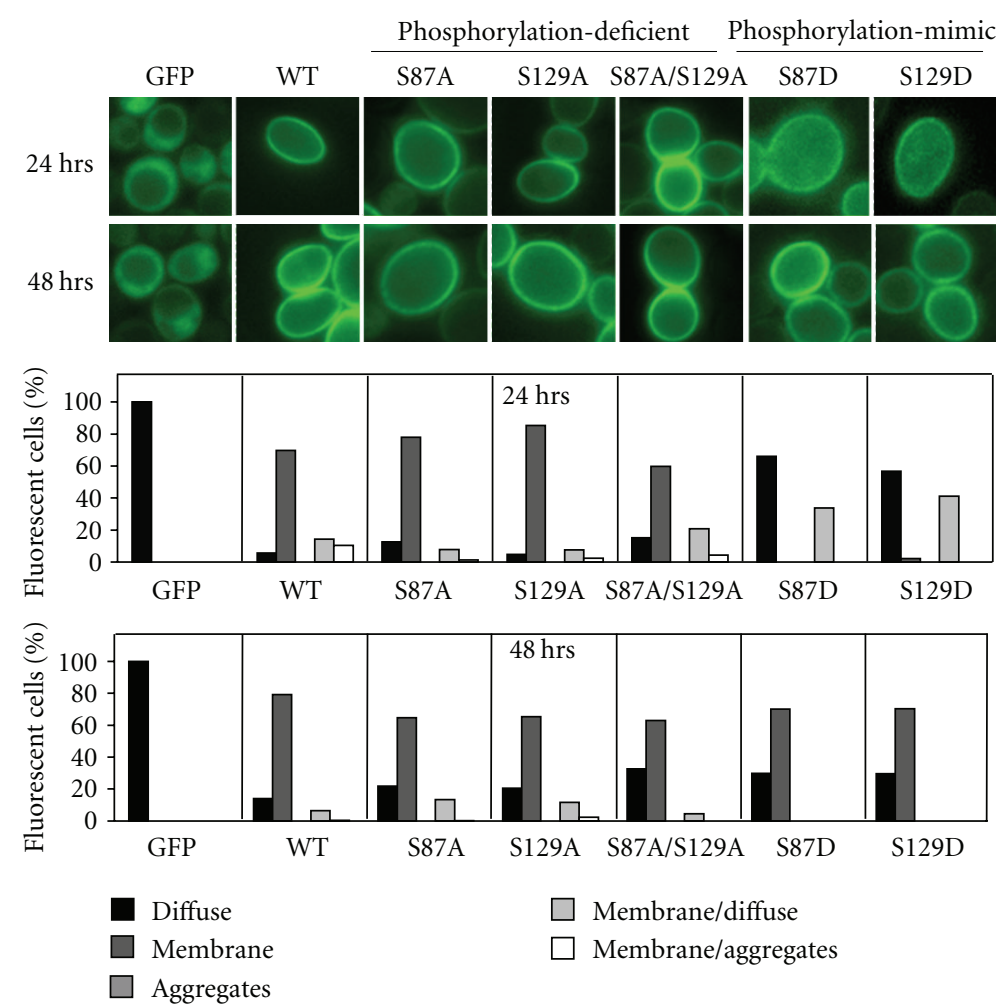

(b) Localization \& Quantification

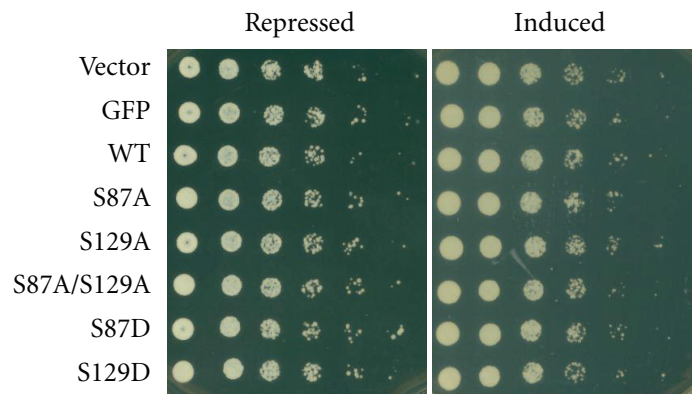

(c) Toxicity

FIGURE 3: Characterization of phosphorylation mutants in BY4741. (a) Western blot of WT, phosphorylation-deficient mutants (S87A, S129A, and S87A/S129A), and phosphorylation-mimic mutants (S87D, S129D). BY4741 lysates were probed with anti-pS129 (top), antiV5 ( $\alpha$-synuclein; middle), and anti-PGK, which served as a protein-loading control (bottom). WT, S87A, and S87D are phosphorylated at serine-129 $(N=2)$. (b) Live-cell GFP microscopy of BY4741 cells expressing GFP, WT, S87A, S129A, S87A/S129A, S87D, or S129D at 24 and 48 hours (top). Quantification: 750 cells of each type were scored for these localization patterns: cytoplasmically diffuse, and plasma membrane, aggregate, plasma membrane/diffuse, plasma membrane/aggregate (bottom). Phenotypes were plotted as a percent of total cells that fluoresced $(N=2)$. (c) Cells expressing WT, S87A, S129A, S87A/S129A, S87D, or S129D were grown in inducing (galactose) media for 48 hours. Vector alone and GFP served as controls. Equal number of cells were serially diluted 5-fold and spotted onto repressing (glucose) or inducing (galactose) plates and grown for two days (bottom). No phosphorylation-specific toxicity was apparent $(N=3)$. 

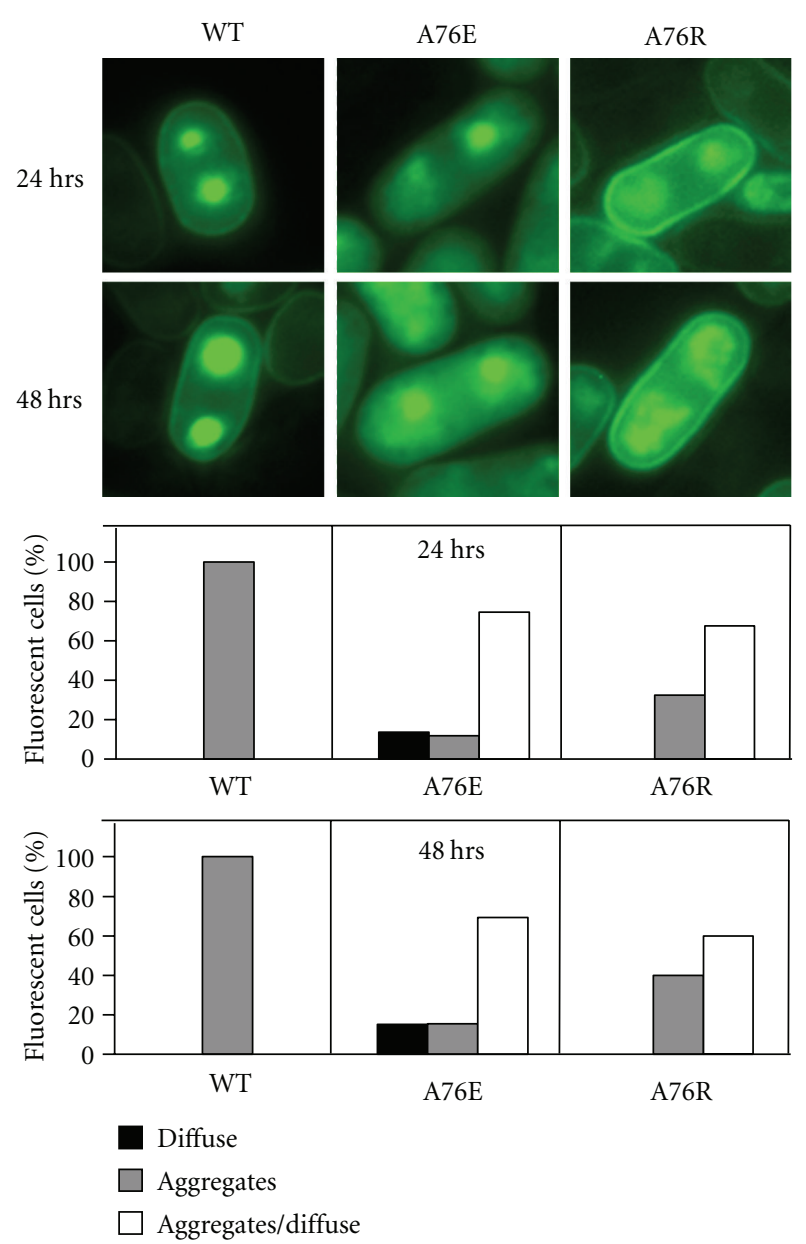

(a) Localization \& Quantification

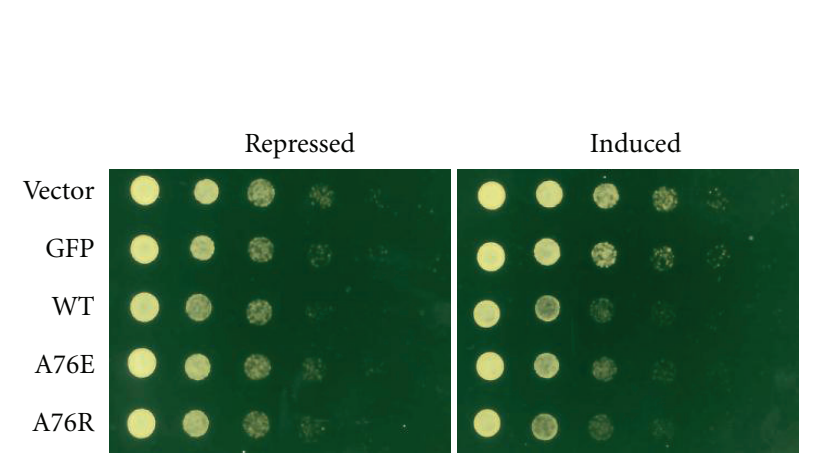

(b) Toxicity

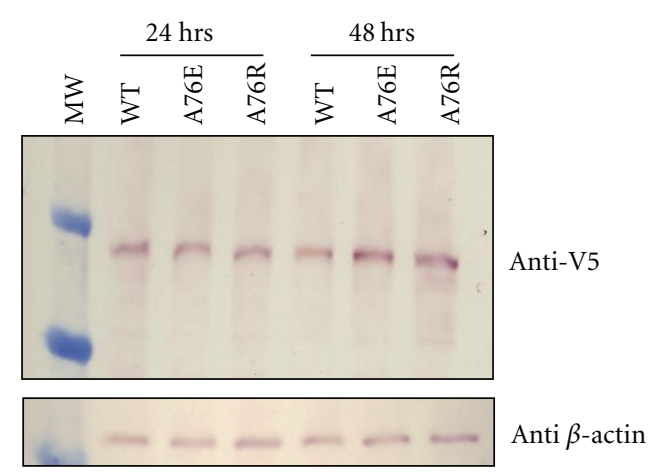

(c) Expression

Figure 4: Characterization of alanine-76 in TCP1. (a) Live-cell GFP microscopy of TCP1 cells expressing WT, A76E, or A76R at 24 and 48 hours (left). Quantification: 750 cells of each type were scored for these localization patterns: diffuse, aggregate, and aggregate/diffuse (right). Phenotypes were plotted as a percent of total cells that fluoresced $(N=2)$. (b) TCP1 cells expressing WT, A76E, or A76R were grown in inducing (EMM-T) media for 48 hours. Vector alone and GFP served as controls. Equal number of cells were serially diluted 5-fold and spotted onto repressing $(\mathrm{EMM}+\mathrm{T})$ or inducing $(\mathrm{EMM}-\mathrm{T})$ plates and grown for two days (right). The A76E and A76R mutants were equally toxic as WT $(N=3)$. (c) Western blot of TCP1 cells expressing WT, A76E, or A76R at 24 and 48 hours. Lysates were probed with anti-V5 ( $\alpha$-synuclein) or anti- $\beta$-actin (loading control). Expression is equivalent between WT and the alanine-76 mutants at 24 and 48 hours $(N=3)$. 
localized back to the plasma membrane by 48 hours (77\%; Figure 5(a)).

We next evaluated how the alanine-76 mutants altered the toxic properties of $\alpha$-synuclein in budding yeast. Fivefold serial dilution spotting indicated that budding yeast cells expressing A76E or A76R grew just as well as WT $\alpha$-synuclein cells (Figure 5(b)).

We lastly determined how $\alpha$-synuclein expression levels changed in the budding yeast as a result of the A76E or A76R mutations. Western blot illustrated no evident difference in expression levels at 24 or 48 hours between cells expressing WT, A76E, or A76R $\alpha$-synuclein (Figure 5(c)).

\section{Discussion}

Both serine phosphorylation on $\alpha$-synuclein and alanine-76 (within its NAC domain) have been implicated in altering $\alpha$ synuclein aggregation and toxicity, but less so in regulating membrane association. Studies examining serine phosphorylation in different model organisms have produced conflicting results, and alanine-76 studies have not yet been well recapitulated in a free-living organism. Here, we show that both serine phosphorylation and alanine-76 significantly regulate the membrane association and aggregation of the protein. We discuss three main findings: (1) $\alpha$-synuclein is phosphorylated at serine-129 in both budding yeast and fission yeast; (2) phosphorylation contributes significantly to aggregation but only moderately impacts membrane association; (3) alanine-76 is relevant to both aggregation and membrane association.

3.1. $\alpha$-Synuclein Is Phosphorylated at Serine-129 in Budding and Fission Yeasts. Western blotting with the anti-pS129 antibody demonstrates that serine-129 on $\alpha$-synuclein is phosphorylated in both of our yeast models. Whether serine87 phosphorylation occurs in yeasts still remains to be determined. Our data confirms an initial report in budding yeast [46] and extends it to fission yeast that yeasts possess protein kinases that can phosphorylate human $\alpha$-synuclein. Identifying the yeast protein kinase(s) may facilitate progress if $\alpha$-synuclein phosphorylation is, in fact, pathogenic and if human kinase homologues exist. Previous studies have shown that $\alpha$-synuclein is phosphorylated in human cell culture [21], transgenic Drosophila [47], and transfected rats [48] and mice [49]. Several kinases have demonstrated the potential to phosphorylate $\alpha$-synuclein at serine-129 in vitro, including casein kinase I and II [21, 48], G proteincoupled receptor kinases 1, 2, 5, and 6 [50], LRRK2 [51], and the polo-like kinases [52, 53]. However, the identity of the kinases responsible for serine-129 and serine-87 phosphorylation in Lewy bodies is still unknown.

3.2. Phosphorylation Status Regulates Aggregation and Membrane Association. $\alpha$-Synuclein forms intracellular aggregates in our fission yeast model [45]. These could either be true Lewy body-like inclusions or they could be intracellular membranous structures derived from the secretory pathway that have coalesced together. Our data indicates that $\alpha$ synuclein serine phosphorylation does regulate $\alpha$-synuclein aggregation as both constitutive phosphorylation and the lack of it significantly alter the $\alpha$-synuclein aggregation pattern. Therefore, we suggest that the intracellular concentration of phosphorylated $\alpha$-synuclein helps determine whether the protein aggregates, bind membranes, or remain cytoplasmically diffuse, and this complex relationship is likely cell/organismal specific. It may partly explain why several past studies that have investigated serine phosphorylation's role in $\alpha$-synuclein aggregation and toxicity have not found consistent results across organismal models [22, 26$28,30]$.

This is the first study to demonstrate phosphorylation's role in altering $\alpha$-synuclein's interaction with endomembranes and with the plasma membrane, providing live-cell support for past in vitro demonstration that serine phosphorylation decreases membrane association [25]. Specifically, in fission yeast, blocking serine phosphorylation enhances $\alpha$ synuclein to endomembrane structures, most likely due to resdistribution of $\alpha$-synuclein that is now less aggregated. In budding yeast, constitutive serine phosphorylation decreases $\alpha$-synuclein plasma membrane association, at least in the first 24 hours. The differences between the yeasts could be due to $\alpha$-synuclein associating differently with plasma membrane than it does diverse endomembrane structures, and this could be the result of differential phospholipid interactions and/or associations with membrane-specific proteins that may be cell/organismal dependent.

3.3. Alanine-76 Regulates Membrane Association and Aggregation. In support of our hypothesis, both A76E and A76R $\alpha$-synuclein mutants decrease plasma membrane association in budding yeast and decrease aggregation in fission yeast, but to differing extents, emphasizing the critical importance of this amino acid initially indicated in vitro and in cell culture [19, 54]. More recently, deletions of alanine-76 and alanine-77 decreased maturation of $\alpha$-synuclein fibril formation and increased oligomerization [37]. Future work should aim to identify other amino acids that contribute significantly to the biochemical properties of $\alpha$-synuclein. In fission yeast, neither WT nor A30P and A53T familial synuclein PD mutants associate with its plasma membrane [45], but A76R does, which suggests that specifically localized positively charged amino acids might help drive $\alpha$-synuclein membrane association. In support of this notion, the E46K synuclein familial PD mutant (with its lysine charge) extensively and selectively associates with endomembrane structures in some fission yeast strains and associates more strongly than WT and A53T synuclein with the plasma membrane in budding yeast (Fiske et al., manuscript in press ISRN Neurology).

3.4. Lack of Toxicity. The exact link between serine phosphorylation of $\alpha$-synuclein and neurotoxicity is controversial. Some studies support more phosphorylation [27], while others support less phosphorylation [28, 29] or find no link at all [30]. Our findings in yeasts support the 

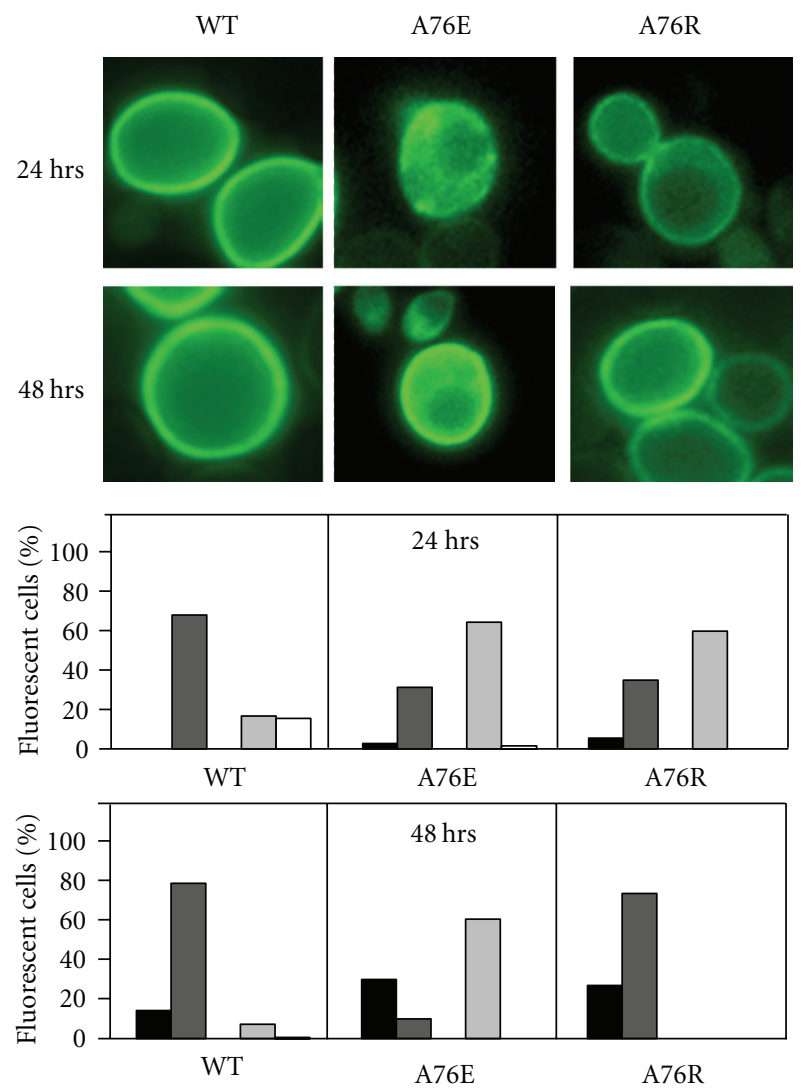
Diffuse
$\square$ Membrance
Membrance/diffuse
$\square$ Aggregates
$\square$ Membrance/aggregates

(a) Localization \& Quantification

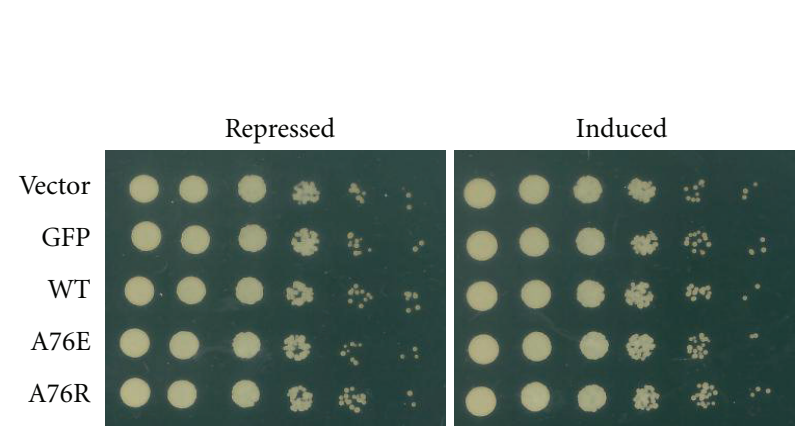

(b) Toxicity

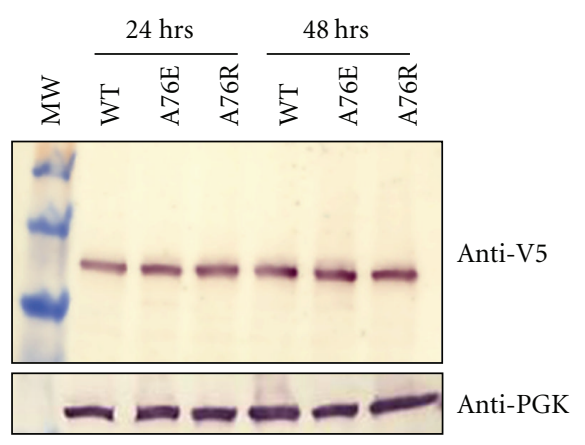

(c) Expression

Figure 5: Characterization of alanine-76 in BY4741. (a) Live-cell GFP microscopy of BY4741 cells expressing WT, A76E, or A76R at 24 and 48 hours (left). Quantification: 750 cells of each type were scored for these localization patterns: cytoplasmically diffuse, and plasma membrane, aggregate, plasma membrane/diffuse, plasma membrane/aggregate (right). Phenotypes were plotted as a percent of total cells that fluoresced $(N=2)$. (b) BY4741 cells expressing WT, A76E, or A76R were grown in inducing (galactose) media for 48 hours. Vector alone and GFP served as controls. Equal number of cells were serially diluted 5-fold and spotted onto repressing (glucose) or inducing (galactose) plates and grown for two days (right). No toxicity was apparent in budding yeast $(N=3)$. (c) Western blot of BY4741 cells expressing WT, A76E, or A76R at 24 and 48 hours. Lysates were probed with anti-V5 ( $\alpha$-synuclein) or anti-PGK. Expression is equivalent between WT and the alanine-76 mutants at 24 and 48 hours. 
notion that $\alpha$-synuclein serine phosphorylation does not significantly influence toxicity. It surprised us that, despite the variety of $\alpha$-synuclein localization phenotypes induced with phosphorylation-mimic or phosphorylation-deficient mutants in both yeasts, none of these changes induced toxicity. Recent evidence has suggested that phosphorylation might promote the formation of protective, mature fibrils rather than the potentially toxic intermediates [31]. Perhaps in our yeast models, enough toxic intermediates did not build up with any of our phosphorylation mutants. Additionally, opposing influences of tyrosine phosphorylation and serine phosphorylation on $\alpha$-synuclein-dependent toxicity have been proposed [55], which may have masked toxicity resulting from mimicking or blocking serine phosphorylation.

Several lines of evidence also support the notion that aggregation is a protective mechanism employed by cells to prevent $\alpha$-synuclein toxicity. For example, the A30P familial mutant promotes the formation of protofibrils rather than mature amyloid fibrils $[56,57]$, and these toxic protofibrils coincide with the fragmentation of the Golgi apparatus and loss of cell viability in a cell culture model [58]. If aggregates are protective, then reducing aggregation should increase $\alpha$-synuclein-dependent toxicity, but both A76E and A76R mutants decreased aggregation in fission yeast without increasing toxicity, suggesting that either not enough toxic protofibrils were generated or residual aggregation provided enough protection. Several labs, including ours, have suggested that membrane association is also a contributing factor to $\alpha$-synuclein toxicity [41, 59]. Yet, increased endomembrane interactions or decreased plasma membrane interactions exhibited by alanine- 76 and/or specific phosphorylation mutants do not alter toxicity in either yeast model. One reason could simply be that our budding yeast model might not express sufficient levels of $\alpha$-synuclein to induce toxicity or that, in both yeasts, one or more other cellular factors pathways need to be further comprised [39], which include oxidative defense [41], proteasome [41], ER/Golgi Pathway [42], endocytosis ([60]; Perez et al., manuscript in preparation), or autophagy (Konnikova et al., manuscript in preparation).

\section{Materials and Methods}

4.1. $\alpha$-Synuclein Constructs. Wild-type (WT) $\alpha$-synucleinGFP in pYES2.1/V5-His-TOPO budding yeast expression vector (Invitrogen) or pNMT1/V5-His-TOPO was prepared as described by Fiske et al. (manuscript current in press with ISRN Neurology). The alanine-76 and phosphorylation mutants were created using site-directed mutagenesis (Invitrogen) with the above $\alpha$-synuclein-GFP vectors as templates, using the following primers:

A76E FP: 5' ATGTAGGCTCCAAAAACAAGAAGGGAGTGGTGC 3'

A76E RP: 5' CTTGGTTTTGGAGCCTACATAGAGAACACC $3^{\prime}$

A76R FP: $5^{\prime}$ ATGTAGGCTCCAAAAACAAGAAGGGAGTGGTGC $3^{\prime}$
A76R RP: 5' CTTGGTTTTGGAGCCTACATAGAGAACACC $3^{\prime}$

S87A FP: 5' ATGTAGGCTCCAAAAACAAGAAGGGAGTGGTGC 3'

S87A RP: 5' CTTGGTTTTGGAGCCTACATAGAGAACACC $3^{\prime}$

S87D FP: 5' ATGTAGGCTCCAAAAACAAGAAGGGAGTGGTGC $3^{\prime}$

S87D RP: 5' CTTGGTTTTGGAGCCTACATAGAGAACACC $3^{\prime}$

S129A FP: 5' ATGTAGGCTCCAAAAACAAGAAGGGAGTGGTGC 3'

S129A RP: 5' CTTGGTTTTGGAGCCTACATAGAGAACACC 3'

S129D FP: 5' ATGTAGGCTCCAAAAACAAGAAGGGAGTGGTGC $3^{\prime}$

S129D RP: 5' CTTGGTTTTGGAGCCTACATAGAGAACACC $3^{\prime}$

The S87A/S129A mutant was created by first making the S87A mutant, which was then the template to make the S129A mutation. Mutations were sequenced at University of Chicago to confirm successful substitution. The parent pYES2.1 vector for budding yeast (Invitrogen) and parent pNMT1 pREP vector (gift from Judy Potashkin, Rosalind Franklin University of medicine and sciences, North Chicago, IL, USA) were controls.

4.2. Yeast Strains. Parent budding yeast strain was BY4741 (MATa his $3 \Delta 1$ leu2 $\Delta 0$ met15 $\Delta 0$ ura3 $\Delta 0$ ), BY4742 (MAT $\alpha$ his $3 \Delta 1$ leu2 $\Delta 0$ lys $2 \Delta 0$ met $15 \Delta 0$ ura3 $\Delta 0$ ), and BY4743 $(\mathrm{MATa} / \alpha$ his $3 \Delta 1$ leu2 $\Delta 0$ lys $2 \Delta 0$ ura $3 \Delta 0$ ). Fission yeast strains TCP1 (h-leu1-32) and SP3 (h+leu1-32) were provided by Invitrogen and Judy Potashkin (Rosalind Franklin University of Medicine and Science), respectively.

4.3. S. cerevisiae $\alpha$-Synuclein Expression. $\alpha$-Synuclein expression plasmid vectors were transformed into yeast strains as described in [41]. For selection, yeasts cells were grown on synthetic-complete media lacking uracil (SC-Ura). In the pYES2 vector, $\alpha$-synuclein expression was controlled through a tightly regulated galactose-inducible promoter (Gal1). Yeast were grown to mid-log phase in SC-Ura glucose (2\%) or SC-Ura raffinose $(2 \%)$ media at $30^{\circ} \mathrm{C}$. Cells were washed with water and diluted to log-phase $\left(5 \times 10^{6}\right.$ cells $\left./ \mathrm{mL}\right)$ in SCUra galactose (2\%) media to induce $\alpha$-synuclein expression.

4.4. S. pombe $\alpha$-Synuclein Expression. S. pombe strains were transformed with pNMT1 vectors using the lithium-acetate transformation method [45]. Transformed cells were selected by growth on pombe dropout medium-leucine (PDM-Leu) containing $10 \mu \mathrm{M}$ thiamine. $\alpha$-Synuclein was expressed by growth in thiamine-lacking media as described in [44].

4.5. Western Analysis. Budding or fission yeast cells at $2.5 \times 10^{7}$ cells $/ \mathrm{mL}$ concentration were washed twice with 
$100 \mathrm{mM} \mathrm{NaN}_{3}$ and solubilized in electrophoresis sample buffer (ESB) [46]. The ESB contained 2\% sodium dodecyl sulfate (SDS), $80 \mathrm{mM}$ Tris (Ph 6.8), 10\% glycerol, $1.5 \%$ dithiothreitol, $1 \mathrm{mg} / \mathrm{mL}$ bromophenol blue, and a cocktail of protease inhibitors and solubilizing agents (1\% Triton$\mathrm{X} 100,1 \mathrm{mM}$ phenylmethylsulfonyl fluoride, $1 \mathrm{mM}$ benzamidine, $1 \mathrm{mM}$ sodium orthovanadate, $0.7 \mathrm{mg} / \mathrm{mL}$ pepstatin A, $0.5 \mathrm{mg} / \mathrm{mL}$ leupeptin, $10 \mathrm{mg} / \mathrm{mL}$ E64, $2 \mathrm{mg} / \mathrm{ml}$ aprotinin, and $2 \mathrm{mg} / \mathrm{mL}$ chymostatin). Lysates were electrophoresed at 130 volts on a $10-20 \%$ Tris-Glycine gel (Invitrogen) with 1X SDS running buffer. SeeBlue (Invitrogen) molecular ladder was used as a standard. Gels were transferred to PVDF membranes using a semidry transfer method and probed using the desired antibodies. To detect $\alpha$-synuclein, a mouse monoclonal anti-V5-AP antibody (Invitrogen) was used at $1: 2000$. Mouse antiphosphoglycerokinase (PGK; molecular probes) was used at $1: 1000$ as a loading control for budding yeast, and anti- $\beta$-actin (Abcam) was used at $1: 1000$ as a loading control for fission yeast. For both, goat antimouse secondary antibody (Invitrogen) was used. Serine-129 phosphorylation blots were probed with a rabbit $\alpha$-synuclein (phospho S129) antibody (ab59264; Abcam) at $1: 500$, followed by a goat antirabbit secondary antibody (Santa Cruz Biotechnology). All blots were visualized by detecting for alkaline-phosphatase activity. All blots were done at least three times.

4.6. OD600 Growth Curve Analysis. Yeast cells were grown in either $10 \mathrm{~mL}$ SC-Ura + glucose (budding yeast) or EMM+T (fission yeast) overnight at $30^{\circ} \mathrm{C}$ and $200 \mathrm{rpm}$. To collect cells, yeast were pelleted at $1500 \times \mathrm{g}$ for 5 minutes at $4^{\circ} \mathrm{C}$. They were washed twice with $5 \mathrm{~mL} \mathrm{H}_{2} \mathrm{O}$, resuspended in $10 \mathrm{~mL}$ $\mathrm{H}_{2} \mathrm{O}$, and counted using a hemocytometer to determine cell density. Flasks containing $25 \mathrm{~mL} \mathrm{SC-Ura} \mathrm{+} \mathrm{galactose}$ (budding yeast) or EMM-T (fission yeast) were inoculated to a density of $2.0 \times 10^{6}$ cells $/ \mathrm{mL}$. Duplicate spectrophotometer $600 \mathrm{~nm}$ absorbance measurements of $1 \mathrm{~mL}$ of cells in a plastic cuvette were taken at $0,3,6,12,18,24,36$, and 48 hours after-induction. The spectrophotometer model was a Hitachi U-2000 Spectrophotometer. A growth curve was generated in Microsoft Excel by plotting the average absorbance readings of three experiments. A Student's $t$-test was used to determine significance.

4.7. Serial Dilution Spotting. Yeast cells were grown in either $10 \mathrm{~mL}$ SC-Ura + glucose (budding yeast) or EMM+T (fission yeast) overnight at $30^{\circ} \mathrm{C}$ and $200 \mathrm{rpm}$. To collect cells, yeasts were pelleted at $1500 \times \mathrm{g}$ for 5 minutes at $4^{\circ} \mathrm{C}$. They were washed twice with $5 \mathrm{~mL} \mathrm{H}_{2} \mathrm{O}$, resuspended in $10 \mathrm{~mL}$ $\mathrm{H}_{2} \mathrm{O}$, and counted using a hemocytometer to determine cell density. $2.0 \times 10^{6}$ cells were removed and pelleted. The supernatant was removed, and cells were resuspended in $1 \mathrm{~mL} \mathrm{H}_{2} \mathrm{O}$. Cells were diluted 5-fold in a 96-well microtiter plate and spotted onto SC-Ura + glucose and Sc-Ura + galactose (budding yeast) or $\mathrm{EMM}+\mathrm{T}$ and $\mathrm{EMM}-\mathrm{T}$ (fission yeast) growth plates. Cells were grown for 24 hours, and pictures were taken using an HP CanoScan scanner. Images were imported into Adobe Photoshop CS2. All spotting experiments were conducted at least three times in triplicate.
4.8. GFP Microscopy. Yeast cells were grown in either $10 \mathrm{~mL}$ $\mathrm{SC}$-Ura + glucose (budding yeast) or EMM+T (fission yeast) overnight at $30^{\circ} \mathrm{C}$ and $200 \mathrm{rpm}$. To collect cells, yeasts were pelleted at $1500 \times \mathrm{g}$ for 5 minutes at $4^{\circ} \mathrm{C}$. They were washed twice with $5 \mathrm{~mL} \mathrm{H}_{2} \mathrm{O}$, resuspended in $10 \mathrm{~mL} \mathrm{H}_{2} \mathrm{O}$, and counted using a hemocytometer to determine cell density. Flasks containing $25 \mathrm{~mL} \mathrm{SC-Ura} \mathrm{+} \mathrm{galactose} \mathrm{(budding} \mathrm{yeast)}$ or EMM-T (fission yeast) were inoculated to a density of $2.0 \times 10^{7}$ cells $/ \mathrm{mL}$. $1 \mathrm{~mL}$ of cell culture was pelleted at $5000 \mathrm{rpm}$ for 1 minute. $900 \mu \mathrm{L}$ of supernatant was removed. The remaining $100 \mu \mathrm{L}$ of cell culture was vortexed, and 5$10 \mu \mathrm{L}$ of sample was pipetted onto a glass slide. Cells were visualized using a Nikon TE2000-U fluorescent microscope, and images were collected and quantified using Metamorph 4.0 software. For each yeast sample, at each time point 750 cells of each type were scored for all or some of these localization patterns: cytoplasmically diffuse, plasma membrane, aggregate, membrane/diffuse, membrane/aggregate, and endomembrane, endomembrane/aggregate, endomembrane/diffuse (bottom). All microscopy experiments were conducted twice.

\section{Acknowledgments}

The authors acknowledge, at Lake Forest College, the following undergraduates: Katrina Brandis, Lokesh Kukreja, Alexandra Ayala, Ray Choi, Jaime Perez, Daniel Sanchez, Kayla Ahlstrand, Peter Sullivan, Madhavi Senagolage, and Natalie Kukulka for editorial comments. S. DebBurman was supported by grants from NIH (R15 grant NS04850801 and NS048508-02) and NSF (CCLI 0310627 and MRI 0115919). K. Solvang was supported by an NIH ARRA summer undergraduate research supplement. S. Herrera was supported by an NIH-NINDS diversity supplement undergraduate research grant. M. Fiske was supported by a Parkinson's Disease Foundation summer undergraduate research fellowship. The authors declare they have no competing interests. M. Fiske, S. Valtierra, M. Zorniak, M. White, S. Herrera, K. Solvang, A. Konnikova, and R. Brezinsky performed experiments. M. Fiske, S. Valtierra, and S. DebBurman wrote the paper. M. Fiske and S. Valtierra are co-first authors to this paper.

\section{References}

[1] M. G. Spillantini, R. A. Crowther, R. Jakes, M. Hasegawa, and M. Goedert, " $\alpha$-synuclein in filamentous inclusions of Lewy bodies from Parkinson's disease and dementia with Lewy bodies," Proceedings of the National Academy of Sciences of the United States of America, vol. 95, no. 11, pp. 6469-6473, 1998.

[2] K. Wakabayashi, Y. Toyoshima, K. Awamori et al., "Restricted occurrence of Lewy bodies in the dorsal vagal nucleus in a patient with late-onset parkinsonism," Journal of the Neurological Sciences, vol. 165, no. 2, pp. 188-191, 1999.

[3] D. J. Burn and E. Jaros, "Multiple system atrophy: cellular and molecular pathology," Journal of Clinical Pathology, vol. 54, no. 6, pp. 419-426, 2001.

[4] J. L. Heidebrink, "Is dementia with Lewy bodies the second most common cause of dementia?" Journal of Geriatric Psychiatry and Neurology, vol. 15, no. 4, pp. 182-187, 2002. 
[5] M. Goedert, "Alpha-synuclein and neurodegenerative diseases," Nature Reviews Neuroscience, vol. 2, no. 7, pp. 492-501, 2001.

[6] E. R. Dorsey, R. Constantinescu, J. P. Thompson et al., "Projected number of people with Parkinson disease in the most populous nations, 2005 through 2030," Neurology, vol. 68, no. 5, pp. 384-386, 2007.

[7] M. H. Polymeropoulos, C. Lavedan, E. Leroy et al., "Mutation in the $\alpha$-synuclein gene identified in families with Parkinson's disease," Science, vol. 276, no. 5321, pp. 2045-2047, 1997.

[8] R. Krüger, W. Kuhn, K. L. Leenders et al., "Familial parkinsonism with synuclein pathology: clinical and PET studies of A30P mutation carriers," Neurology, vol. 56, no. 10, pp. 1355$1362,2001$.

[9] J. J. Zarranz, J. Alegre, J. C. Gómez-Esteban et al., "The new mutation, E46K, of $\alpha$-synuclein causes Parkinson and Lewy body dementia," Annals of Neurology, vol. 55, no. 2, pp. 164173, 2004.

[10] A. B. Singleton, M. Farrer, J. Johnson et al., " $\alpha$-synuclein locus triplication causes Parkinson's disease," Science, vol. 302, no. 5646, p. 841, 2003.

[11] M. C. Chartier-Harlin, J. Kachergus, C. Roumier et al., " $\alpha$ synuclein locus duplication as a cause of familial Parkinson's disease," The Lancet, vol. 364, no. 9440, pp. 1167-1169, 2004.

[12] D. M. Maraganore, M. de Andrade, A. Elbaz et al., "Collaborative analysis of $\alpha$-synuclein gene promoter variability and Parkinson disease," Journal of the American Medical Association, vol. 296, no. 6, pp. 661-670, 2006.

[13] K. Ueda, H. Fukushima, E. Masliah et al., "Molecular cloning of cDNA encoding an unrecognized component of amyloid in Alzheimer disease," Proceedings of the National Academy of Sciences of the United States of America, vol. 90, no. 23, pp. 11282-11286, 1993.

[14] J. M. George, “The synucleins," Genome Biology, vol. 3, no. 1, article 3002, 2002.

[15] D. D. Murphy, S. M. Rueter, J. Q. Trojanowski, and V. M. Y. Lee, "Synucleins are developmentally expressed, and $\alpha$ synuclein regulates the size of the presynaptic vesicular pool in primary hippocampal neurons," Journal of Neuroscience, vol. 20, no. 9, pp. 3214-3220, 2000.

[16] K. A. Jellinger, "Formation and development of Lewy pathology: a critical update," Journal of Neurology, vol. 256, no. 3, pp. S270-S279, 2009.

[17] K. Beyer, "Mechanistic aspects of Parkinson's disease: $\alpha$ synuclein and the biomembrane," Cell Biochemistry and Biophysics, vol. 47, no. 2, pp. 285-299, 2007.

[18] H. Shimura, M. G. Schlossmacher, N. Hattori et al., "Ubiquitination of a new form of $\alpha$-synuclein by parkin from human brain: implications for Parkinson's disease," Science, vol. 293, no. 5528, pp. 263-269, 2001.

[19] B. I. Giasson, I. V. J. Murray, J. Q. Trojanowski, and V. M. Y. Lee, "A hydrophobic stretch of 12 amino acid residues in the middle of $\alpha$-synuclein is essential for filament assembly," Journal of Biological Chemistry, vol. 276, no. 4, pp. 2380-2386, 2001.

[20] R. Hodara, E. H. Norris, B. I. Giasson et al., "Functional consequences of $\alpha$-synuclein tyrosine nitration: diminished binding to lipid vesicles and increased fibril formation," Journal of Biological Chemistry, vol. 279, no. 46, pp. 4774647753, 2004.

[21] M. Okochi, J. Walter, A. Koyama et al., "Constitutive phosphorylation of the Parkinson's disease associated $\alpha$-synuclein," Journal of Biological Chemistry, vol. 275, no. 1, pp. 390-397, 2000.
[22] H. Fujiwara, M. Hasegawa, N. Dohmae et al., " $\alpha$-synuclein is phosphorylated in synucleinopathy lesions," Nature Cell Biology, vol. 4, no. 2, pp. 160-164, 2002.

[23] F. Chiti, M. Stefani, N. Taddel, G. Ramponi, and C. M. Dobson, "Rationalization of the effects of mutations on peptide and protein aggregation rates," Nature, vol. 424, no. 6950, pp. 805-808, 2003.

[24] H. J. Koo, H. J. Lee, and H. Im, "Sequence determinants regulating fibrillation of human $\alpha$-synuclein," Biochemical and Biophysical Research Communications, vol. 368, no. 3, pp. 772778, 2008.

[25] K. E. Paleologou, A. Oueslati, G. Shakked et al., "Phosphorylation at S87 is enhanced in synucleinopathies, inhibits $\alpha$-synuclein oligomerization, and influences synuclein-membrane interactions," Journal of Neuroscience, vol. 30, no. 9, pp. 3184-3198, 2010.

[26] W. W. Smith, R. L. Margolis, X. Li et al., " $\alpha$-synuclein phosphorylation enhances eosinophilic cytoplasmic inclusion formation in SH-SY5Y cells," Journal of Neuroscience, vol. 25, no. 23, pp. 5544-5552, 2005.

[27] L. Chen and M. B. Feany, " $\alpha$-synuclein phosphorylation controls neurotoxicity and inclusion formation in a Drosophila model of Parkinson disease," Nature Neuroscience, vol. 8, no. 5, pp. 657-663, 2005.

[28] O. S. Gorbatyuk, S. Li, L. F. Sullivan et al., "The phosphorylation state of Ser-129 in human $\alpha$-synuclein determines neurodegeneration in a rat model of Parkinson disease," Proceedings of the National Academy of Sciences of the United States of America, vol. 105, no. 2, pp. 763-768, 2008.

[29] S. A. da Silveira, B. L. Schneider, C. Cifuentes-Diaz et al., "Phosphorylation does not prompt, nor prevent, the formation of $\alpha$-synuclein toxic species in a rat model of Parkinson's disease," Human Molecular Genetics, vol. 18, no. 5, pp. 872-887, 2009.

[30] N. R. McFarland, Z. Fan, K. Xu et al., “ $\alpha$-synuclein S129 phosphorylation mutants do not alter nigrostriatal toxicity in a rat model of parkinson disease," Journal of Neuropathology and Experimental Neurology, vol. 68, no. 5, pp. 515-524, 2009.

[31] V. N. Uversky and A. L. Fink, "Amino acid determinants of $\alpha$ synuclein aggregation: putting together pieces of the puzzle," FEBS Letters, vol. 522, no. 1-3, pp. 9-13, 2002.

[32] A. M. Bodles, D. J. S. Guthrie, B. Greer, and G. Brent Irvine, "Identification of the region of non-A $\beta$ component (NAC) of Alzheimer's disease amyloid responsible for its aggregation and toxicity," Journal of Neurochemistry, vol. 78, no. 2, pp. 384395,2001

[33] W. Li, N. West, E. Colla et al., "Aggregation promoting Cterminal truncation of $\alpha$-synuclein is a normal cellular process and is enhanced by the familial Parkinson's disease-linked mutations," Proceedings of the National Academy of Sciences of the United States of America, vol. 102, no. 6, pp. 2162-2167, 2005.

[34] P. H. Weinreb, W. Zhen, A. W. Poon, K. A. Conway, and P. T. Lansbury Jr., "NACP, a protein implicated in Alzheimer's disease and learning, is natively unfolded," Biochemistry, vol. 35, no. 43, pp. 13709-13715, 1996.

[35] H. Han, P. H. Weinreb, and P. T. Lansbury Jr., "The core Alzheimer's peptide NAC forms amyloid fibrils which seed and are seeded by beta-amyloid: is NAC a common trigger or target in neurodegenerative disease?" Chemistry and Biology, vol. 2, no. 3, pp. 163-169, 1995.

[36] A. Iwai, M. Yoshimoto, E. Masliah, and T. Saitoh, "Non$\mathrm{A} \beta$ component of Alzheimer's disease amyloid (NAC) is amyloidogenic," Biochemistry, vol. 34, no. 32, pp. 1013910145, 1995. 
[37] E. A. Waxman, J. R. Mazzulli, and B. I. Giasson, "Characterization of hydrophobic residue requirements for $\alpha$-synuclein fibrillization," Biochemistry, vol. 48, no. 40, pp. 9427-9436, 2009.

[38] T. F. Outeiro and S. Lindquist, "Yeast cells provide insight into alpha-synuclein biology and pathobiology," Science, vol. 302, no. 5651, pp. 1772-1775, 2003.

[39] S. Willingham, T. F. Outeiro, M. J. DeVit, S. L. Lindquist, and P. J. Muchowski, "Yeast genes that enhance the toxicity of a mutant huntingtin fragment or $\alpha$-synuclein," Science, vol. 302, no. 5651, pp. 1769-1772, 2003.

[40] P. Zabrocki, K. Pellens, T. Vanhelmont et al., "Characterization of $\alpha$-synuclein aggregation and synergistic toxicity with protein tau in yeast," FEBS Journal, vol. 272, no. 6, pp. 1386-1400, 2005.

[41] N. Sharma, K. A. Brandis, S. K. Herrera et al., “ $\alpha$-synuclein budding yeast model: toxicity enhanced by impaired proteasome and oxidative stress," Journal of Molecular Neuroscience, vol. 28, no. 2, pp. 161-178, 2006.

[42] C. Dixon, N. Mathias, R. M. Zweig, D. A. Davis, and D. S. Gross, " $\alpha$-synuclein targets the plasma membrane via the secretory pathway and induces toxicity in yeast," Genetics, vol. 170, no. 1, pp. 47-59, 2005.

[43] J. H. Soper, S. Roy, A. Stieber et al., " $\alpha$-synuclein-induced aggregation of cytoplasmic vesicles in Saccharomyces cerevisiae," Molecular Biology of the Cell, vol. 19, no. 3, pp. 1093$1103,2008$.

[44] K. Vamvaca, M. J. Volles, and P. T. Lansbury Jr., "The first Nterminal amino acids of $\alpha$-synuclein are essential for $\alpha$-helical structure formation in vitro and membrane binding in yeast," Journal of Molecular Biology, vol. 389, no. 2, pp. 413-424, 2009.

[45] K. A. Brandis, I. F. Holmes, S. J. England, N. Sharma, L. Kukreja, and S. K. DebBurman, " $\alpha$-synuclein fission yeast model: concentration-dependent aggregation without plasma membrane localization or toxicity," Journal of Molecular Neuroscience, vol. 28, no. 2, pp. 179-192, 2006.

[46] E. Yeger-Lotem, L. Riva, L. J. Su et al., "Bridging highthroughput genetic and transcriptional data reveals cellular responses to alpha-synuclein toxicity," Nature Genetics, vol. 41, no. 3, pp. 316-323, 2009.

[47] M. Takahashi, H. Kanuka, H. Fujiwara et al., "Phosphorylation of $\alpha$-synuclein characteristic of synucleinopathy lesions is recapitulated in $\alpha$-synuclein transgenic Drosophila," Neuroscience Letters, vol. 336, no. 3, pp. 155-158, 2003.

[48] M. Yamada, T. Iwatsubo, Y. Mizuno, and H. Mochizuki, "Overexpression of $\alpha$-synuclein in rat substantia nigra results in loss of dopaminergic neurons, phosphorylation of $\alpha$-synuclein and activation of caspase-9: resemblance to pathogenetic changes in Parkinson's disease," Journal of Neurochemistry, vol. 91, no. 2, pp. 451-461, 2004.

[49] E. A. Waxman and B. I. Giasson, "Specificity and regulation of casein kinase-mediated phosphorylation of $\alpha$-synuclein," Journal of Neuropathology and Experimental Neurology, vol. 67, no. 5, pp. 402-416, 2008.

[50] A. N. Pronin, A. J. Morris, A. Surguchov, and J. L. Benovic, "Synucleins are a novel class of substrates for G proteincoupled receptor kinases," Journal of Biological Chemistry, vol. 275, no. 34, pp. 26515-26522, 2000.

[51] H. Qing, W. Wong, E. G. McGeer, and P. L. McGeer, "Lrrk2 phosphorylates alpha synuclein at serine 129: Parkinson disease implications," Biochemical and Biophysical Research Communications, vol. 387, no. 1, pp. 149-152, 2009.

[52] K. J. Inglis, D. Chereau, E. F. Brigham et al., "Polo-like kinase 2 (PLK2) phosphorylates $\alpha$-synuclein at serine 129 in central nervous system," Journal of Biological Chemistry, vol. 284, no. 5, pp. 2598-2602, 2009.

[53] M. K. Mbefo, K. E. Paleologou, A. Boucharaba et al., "Phosphorylation of synucleins by members of the polo-like kinase family," Journal of Biological Chemistry, vol. 285, no. 4, pp. 2807-2822, 2010.

[54] M. Periquet, T. Fulga, L. Myllykangas, M. G. Schlossmacher, and M. B. Feany, "Aggregated $\alpha$-synuclein mediates dopaminergic neurotoxicity in vivo," Journal of Neuroscience, vol. 27, no. 12, pp. 3338-3346, 2007.

[55] L. Chen, M. Periquet, XU. Wang et al., "Tyrosine and serine phosphorylation of $\alpha$-synuclein have opposing effects on neurotoxicity and soluble oligomer formation," Journal of Clinical Investigation, vol. 119, no. 11, pp. 3257-3265, 2009.

[56] P. T. Lansbury Jr., "Evolution of amyloid: what normal protein folding may tell us about fibrillogenesis and disease," Proceedings of the National Academy of Sciences of the United States of America, vol. 96, no. 7, pp. 3342-3344, 1999.

[57] M. S. Goldberg and P. T. Lansbury Jr., "Is there a causeand-effect relationship between $\alpha$-synuclein fibrillization and Parkinson's disease?" Nature Cell Biology, vol. 2, no. 7, pp. E115-E119, 2000.

[58] N. Gosavi, H. J. Lee, J. S. Lee, S. Patel, and S. J. Lee, "Golgi fragmentation occurs in the cells with prefibrillar $\alpha$-synuclein aggregates and precedes the formation of fibrillar inclusion," Journal of Biological Chemistry, vol. 277, no. 50, pp. 4898448992, 2002.

[59] P. K. Auluck, G. Caraveo, and S. Lindquist, " $\alpha$-synuclein: membrane interactions and toxicity in parkinson's disease," Annual Review of Cell and Developmental Biology, vol. 26, pp. 211-233, 2010.

[60] T. R. Flower, C. Clark-Dixon, C. Metoyer et al., "YGR198w (YPP1) targets A30P $\alpha$-synuclein to the vacuole for degradation," Journal of Cell Biology, vol. 177, no. 6, pp. 1091-1104, 2007. 


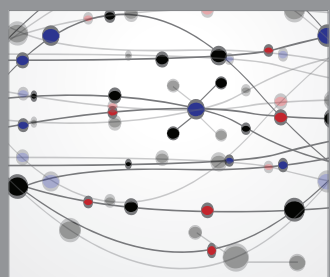

The Scientific World Journal
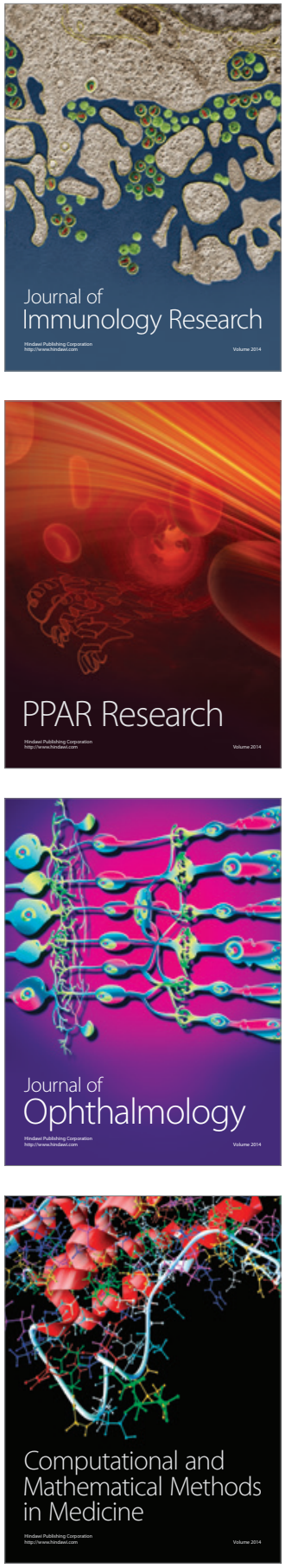

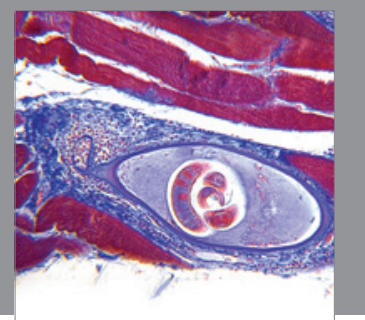

Gastroenterology

Research and Practice
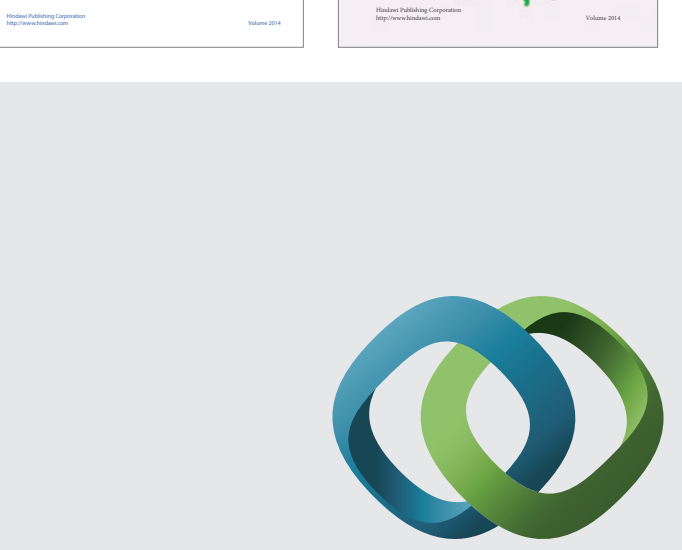

\section{Hindawi}

Submit your manuscripts at

http://www.hindawi.com
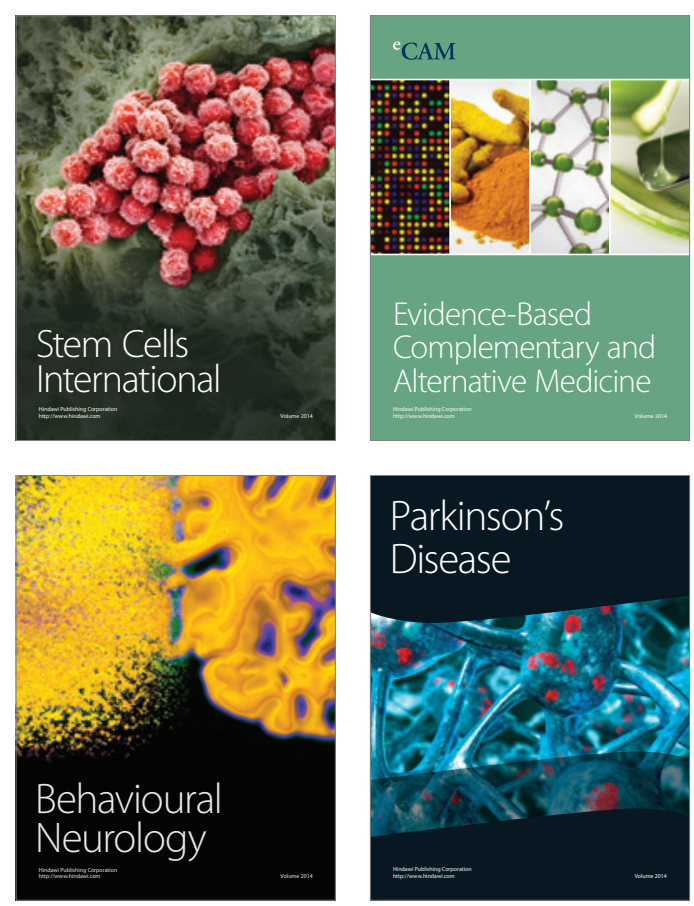

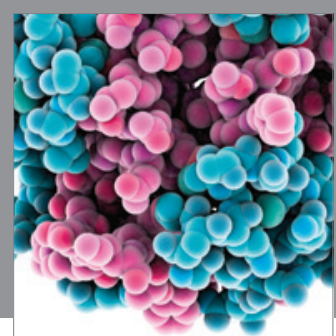

Journal of
Diabetes Research

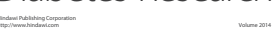

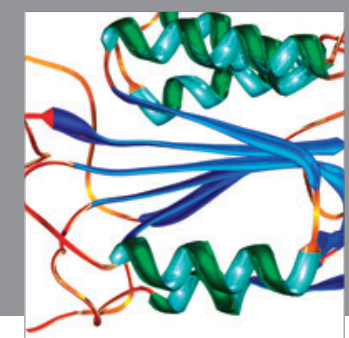

Disease Markers
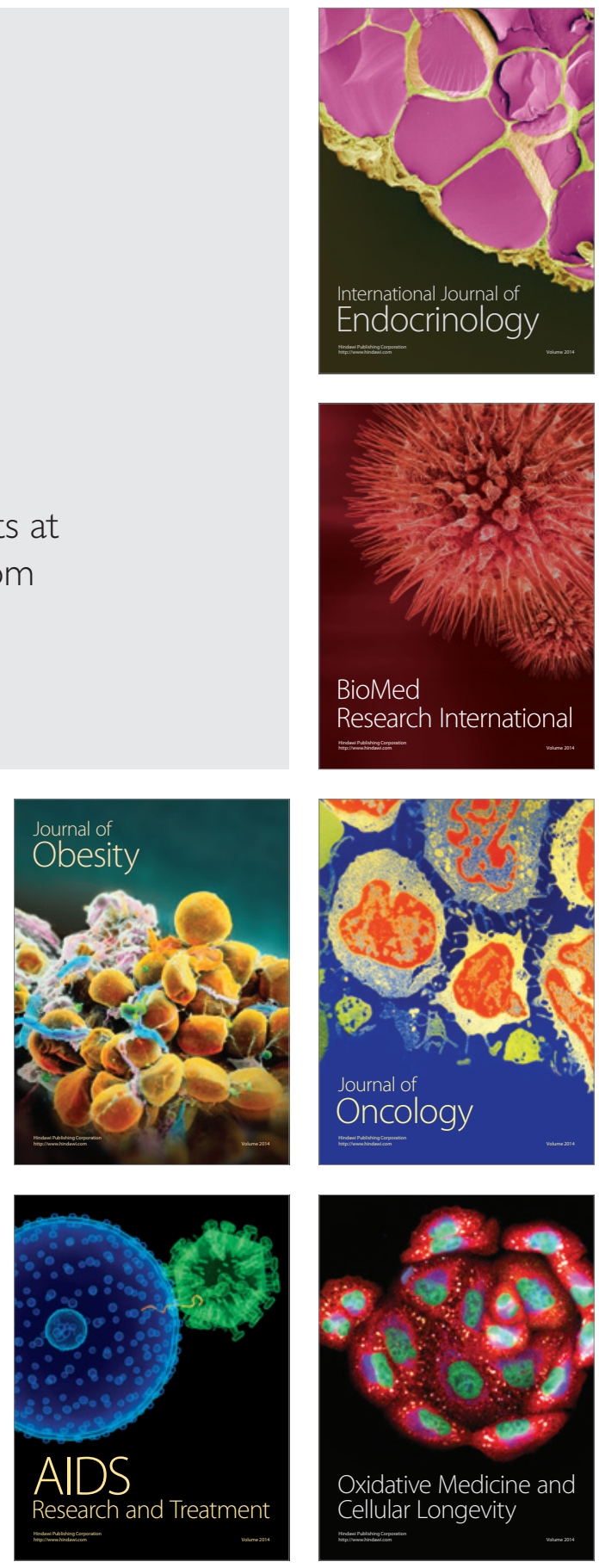